\title{
Simulation of an electric arc in metal welding
}

\author{
Ivan Petrović · Vinko Razl • Marinko Stojkov • Mijat Samardžić
}

Received: date / Accepted: date

\begin{abstract}
This paper describes the proces of electric arc welding in the zone of protective gas, with an emphasis on transmitting metal dropelts via a short ciruit. Parameters of the welding proces and of an electric arc are described, and a mathemacal model for the MIG system is sugessted. Model simulation is completed used Matlab/Simulink package. The proces is simulated using real parameters in order for the output values of the process to corespond to real values obtained by the means of mesasurement.
\end{abstract}

\section{Ivan Petrović}

Josip Juraj Strossmayer University of Osijek

Faculty of Electrical Engineering, Computing and Information Technology Osijek

Kneza Branimira 2B, 31000 Osijek, Croatia

Tel.: +385-31-224600

Fax: +385-31-224605

E-mail: ipetrovic81@gmail.com

Vinko Razl

Josip Juraj Strossmayer University of Osijek

Faculty of Electrical Engineering, Computing and Information Technology Osijek

Kneza Branimira 2B, 31000 Osijek, Croatia

Tel.:+385-31-224600

Fax.:+385-31-224605

E-mail:vrazli@ferit.hr

Marinko Stojkov

University of Slavonski Brod

Trg Stjepana Miletića 12, 35000 Slavonski Brod, Croatia

Tel.:+385-35-446188

Fax.:+385-35-446446

E-mail: mstojkov@unisb.hr

Mijat Samardžić

External associate of Mechanical engineering faculty, University of Slavonski Brod

Trg Stjepana Miletića 12, 35000 Slavonski Brod, Croatia

Tel.:+385-35-446188

Fax.:+385-35-446446

E-mail: samardzic.mijat@gmail.com
Keywords Electric arc - MIG welding · simulation · Matlab/Simulink

\section{Introduction}

This paper deals with simulating an electric arc in the process of welding, with an emphasis on transmitting metal drops during a short circuit with an aim to better understand the electric arc phenomenon and the way its parameters affect the entire process. Due to the complex procedure where the short circuit occurs and the parameters that affect forming and maintaining the electric arc and transmitting the metal via a short circuit, it is difficult to differentiate whether it is applying the electric arc parameters or equipment parameters that have an effect on the welding execution. In order to better understand the electric arc phenomenon in metal welding, a model of the process in accordance with a mathematical model is applied, i.e. in accordance with the Ayrton empirical formula for the electric arc with variables of electric currant and length of the arc, which are obtained by the means of welding, with an emphasis on transmitting metal droplets via a short circuit. The model demonstrates the welding process well, as well as voltage changes and current intensity, arc length applications and change dynamics of a hot droplet that is transmitted from soluble wire to a working piece [?]. This paper will demonstrate a model or electric arc welding via a short circuit designed using a Simulink graphical tool within Matlab program package. 


\section{Transmitting metal via a short circuit}

Transmitting metal via a short circuit is transmitting metal to a working piece by the means of melting an electrode during a short circuit. Transmission of one metal droplet occurs when contact with a melted weld bath is made. Figure 1 shows droplet timeframe, along with waveforms of the voltage and welding current intensity, with an entire cycle of interchanging periods of short circuits and an open arc.

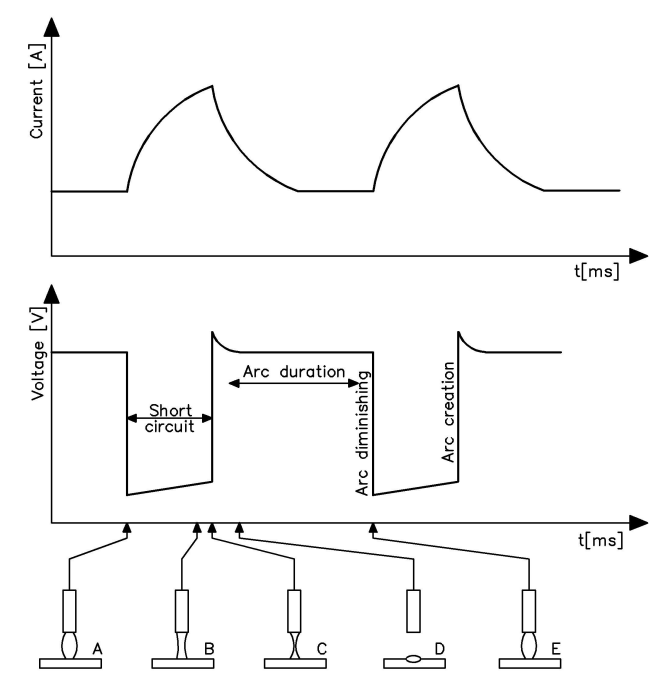

Fig. 1 Oscillogram of transmitting metal via a short circuit $[?]$

Metal transmission occurs in five steps shown in Figure 1, according to the following points:

A - Electrode makes physical contact and creates a melted bridge between the electrode and melted weld bath. Voltage approaches the value of zero and current intensity rises. Rate of current intensity growth depends on the amount of changeable inductance within the source circuit. Rise in current intensity should be high enough to heat up the electrode and to conduct metal transmission, but it should not be too high as that may result in metal splashing and faster droplet detachment.

B - this step shows the effect of electromagnetic forces on the electrode that narrow the metal bridge with the occurrence of a magnetic pinch, i.e. Pinch effect. Due to lower magnetic resistance in overcoming the bridge, current intensity rises and heats up the wire with the Joules effect in the unit of time. This heat is equivalent to the product of wire resistance, current intensity squared and required time.

$\mathrm{C}$ - step in which the melted metal bridge is cut with joined effects of surface tension and electromagnetic forces. Droplet is forced to detach from the tip of the electrode and it moves towards the melted weld bath. $\mathrm{D}$ - there is momentary rise in voltage, while the current intensity starts to exponentially drop back to its initial value. Electric arc is restored. Once it has been established once more, electrode's tip starts to melt and the electrode moves towards the working piece and lessens the distance that occurred with its tip breaking.

$\mathrm{E}$ - electrode makes contact with the melted weld bath once more and preparations for transmitting the second droplet begin.

\subsection{Electric arc charasteristic}

Electric arc in metal welding represents impedance (in regards to welding circuit resistance, but with contribution to capacity and circuit's inductance) for electricity flow. All electric arcs consist of three regions: (1) cathode (potential drops), (2) plasma column and (3) anode (potential drops). Figure 2 shows general layout and structure of the arc, as well as potential between welding electrode and the working piece.

Total arc potential generally increases with the length

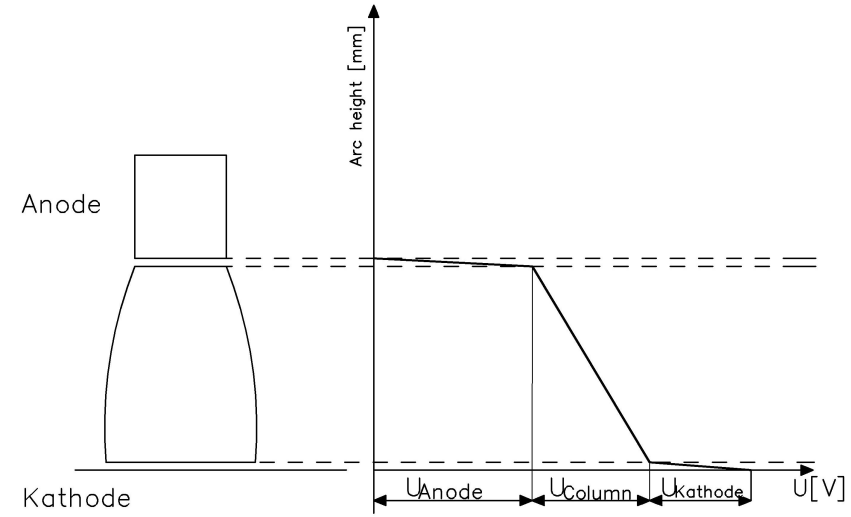

Fig. 2 General layout and structure of the arc and potential between welding electrode and the working piece [?]

of the arc between electrode and the working piece. Voltage drop within the arc is not significantly related to current intensity, as is expected due to the Ohm's law. Total voltage drop in the process of electric-arc welding can be formulated with the following expression:

$U_{\text {arc }}=U_{\text {cathode }}+U_{\text {arc }, \text { column }}+U_{\text {anode }}+U_{\text {electrode }}+$ $U_{\text {droplet }}$

$U_{\text {anode }}$ and $U_{\text {cathode }}$ are not dependant on arc lenght. $U_{\text {arc }}$ column increases with the arc length. 


\subsection{Modeling the welding process}

Mathematical model of the electric-arc welding process, with an emphasis on transmitting via a short circuit, will be described using the following model. The suggested model can be applied to the welding process that oscillates very quickly. Wire melting characteristics and the form of transmitting melted droplets directly affect the parameters of voltage and current intensity of welding. During the short circuit period, we assume that the melting of additional material in the form of melted droplets is continually transmitted from the wire tip towards the working piece at the speed of melting when the short circuit occurs. It is considered that every droplet that forms and grows at the wire tip via electric arc occurrence causes metal transmission to the working piece. Current intensity of the welding process rapidly rises, while the voltage drops momentarily. Metal droplet is formed in the shape of a bridge and reaches the magnetic pinch. Droplet bridge is detached at the moment when welding current reaches its peak value. During the arc period, welding wire is melting due to arc's thermal energy and resistance, a melted metal droplet is formed and arc length is reduced until it reached weld bath which causes the short circuit. Welding voltage is dropping until arc length reaches zero. We conduct the process model in Simulink tool package within the Matlab program.

\subsection{Welding process circuit}

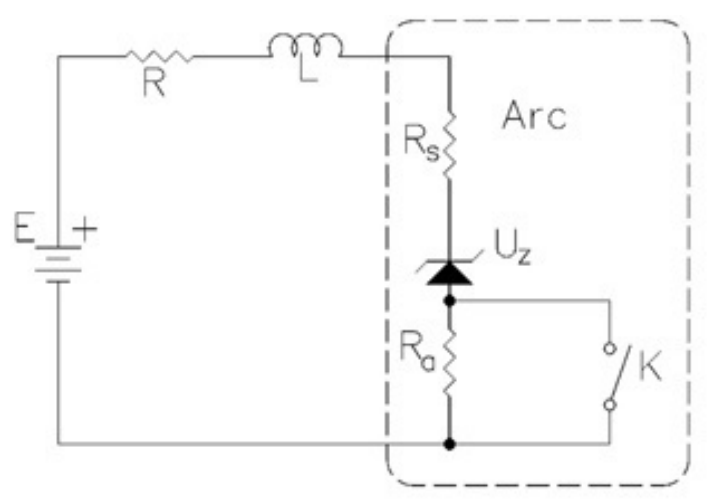

Fig. 3 Circuit equivalent to MIG/MAG welding [?]

We can show welding process circuit in Figure 3. In this picture, intermittent square frame represents the electric arc, $R_{s}$ represents resistance of free wire portion, $R_{a}$ represents the rising portion of arc characteristic, $U_{z}$ represents the arc voltage constant portion, and $K$ represents the switch that closes and opens the circuit during welding. Let us assume that the voltage source has internal resistance $\mathrm{R}$ and inductance $\mathrm{L}$. Transitional welding process with an electric arc can be described with the following expressions.

Current intensity before the short circuit:

$I_{m}=\frac{E-U_{z}}{R+R_{s}+R_{a}}$

Current intensity after the short circuit:

$I_{M}=\frac{E}{R+R_{s}}$

Transitional process when turning on the switch can be described with the following differential equation:

$L \frac{d i}{d t}+\left(R+R_{s}\right)=E$

Transitional process when turning off the switch can be described with the following differential equation:

$i_{s}=I_{M}-\left(I_{M}-I_{m}\right) e^{-\frac{R+R_{s}}{L} i}$

Momentary current intensity after the short circuit can be described with the following expression:

$i_{a}=\left(I_{S M}-I_{m}\right) e^{-\frac{R+R_{s}+R a}{L} i}$

$I_{S M}$ is peak welding current value, and it is equivalent to the maximum current change $\left(\frac{d i_{s}}{d t}\right)$ once the short circuit finishes. Momentary rise in current intensity during the short circuit:

$\frac{d i_{s}}{d t}=\left(I_{M}-I_{m}\right)\left(\frac{R+R_{s}+R_{a}}{L}\right) e^{\frac{R+R_{s}+R_{a}}{L} i}$

Momentary fall in current intensity after the short circuit:

$\frac{d i_{a}}{d t}=-\left(I_{M}-I_{m}\right)\left(\frac{R+R_{s}+R_{a}}{L}\right) e^{-\frac{R+R_{s}+R_{a}}{L} i}$

Rise in welding current intensity after the moment $t=0$, i.e. the short circuit:

$\frac{d i_{s}}{d t}=\left(I_{M}-I_{m}\right)\left(\frac{R+R_{s}}{L}\right)$

Expressions (2) to (8) correspond to waveforms in Figure 4.

Rate at which current intensity changes is dependent on two factors, $\frac{R+R_{s}}{L}$ and $\mathrm{I}_{M}-I_{m}$. The first expression represents a time constant $\frac{1}{T}$, while the second one represents difference in current intensity before and after the short circuit, and it depends on characteristics of the output source. 


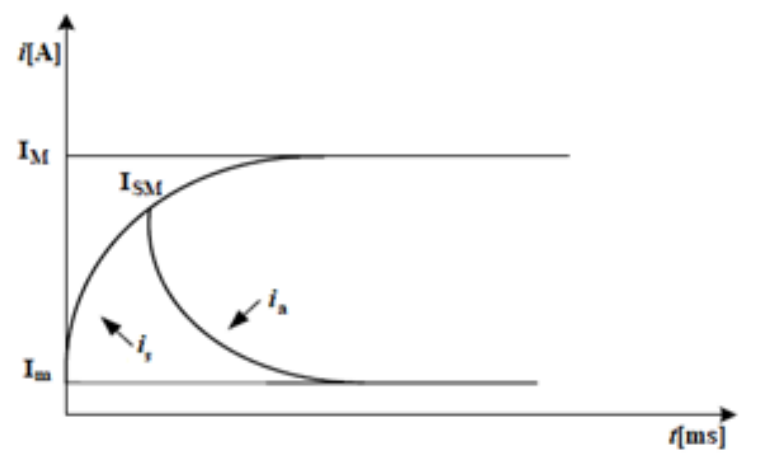

Fig. 4 Welding current intensity when welding with a short circuit [?]

\section{Electric arc model}

Welding model used in this paper is modelled after the one used in Relationship between welding current and voltage in transmitting metal droplets via a short circuit, and it is described with the following expression [?]:

$U_{0}-U_{f}=U_{L}=\frac{d i_{f}(t)}{d t}$

Where the following represents:

$U_{0}$ - voltage drop in welding circuit $[V]$;

$U_{f}-$ weldingvoltage $[\mathrm{V}]$;

$L-$ circuitinductance $[\mu H]$;

$I_{f}(t)-$ welding current intensity $[A]$.

In the arc period, welding voltage is approximately

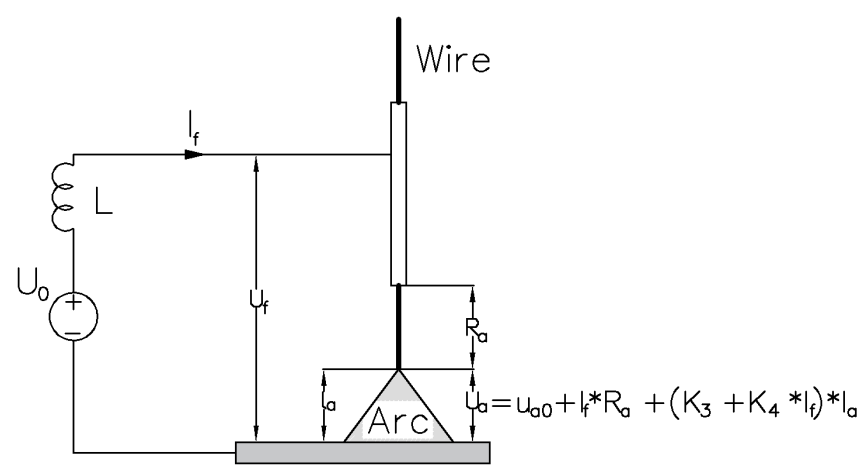

Fig. 5 Welding current intensity when welding with a short circuit

equivalent to arc voltage. Welding voltage during the arc period can be described with the following expression, modelled after the Ayrton formula:

$U_{f} \cong U_{a}=U_{a 0}+R_{a} \cdot I_{f}+\left(K_{3}+I_{f} \cdot K_{4}\right) \cdot l_{a}$
Where the following represents:

$U_{a}$ - total voltage drop of the electric arc $[V]$,

$\mathrm{U}_{f}-$ welding voltage $[\mathrm{V}]$,

$U_{a 0}-$ drop in arc column voltage $[V]$,

$R_{a}-$ electric column resistence $[\Omega]$,

$\left(K_{3}+K_{4} \cdot I_{f}\right)$ - electric field intensity of the arc column (empirical constant) $[\mathrm{V} / \mathrm{mm}]$

$l_{a}-\operatorname{arc~length}[\mathrm{mm}]$

During the short circuit period, droplets make contact with the weld bath and welding voltage is approximately equivalent to the following expression:

$U_{f}=R(t) \cdot I_{f}$

During the welding process, electric arc and short circuit periods are cyclically interchanging, and model premises are as follow:

A - electric arcs length reduces linearly, and initial electric arc length is $20 \%$ greater the electrode diameter. $\mathrm{B}$ - arc voltage drop is equal to the voltage drop during the arc period.

$\mathrm{C}$ - welding current model is a linear model during arc and short circuit periods.

D - welding voltage model and melted droplet bridge model are nonlinear models during arc and short circuit period.

$\mathrm{E}$ - voltage change of the melted droplet bridge is modelled with a U-curve, and it is represented with a sinus curve in the model:

$R(t)=-0,001 \cdot|\sin (500 \pi \cdot t)|+0,011$

Where the minimum $\mathrm{R}(\mathrm{t})$ is $0,001 \Omega$, and maximum $0,01 \Omega$, as is shown in Figure 6 . The entire cycle of metal transmission via a short circuit is set to $\mathrm{ms}$, with a ratio of 5:1 for the periods of electric arc and short circuit.

During the arc period, arc length changes linearly. Arc length is shown as a linear decreasing function with an initial value that is 1,2 times greater than the welding wire, and it repeats itself periodically. Initial arc length value is set to $15 \cdot 10^{-3} \mathrm{~mm}$.

Table 1 Initial process parameters

\begin{tabular}{ll}
\hline Parameter & Value \\
\hline$U_{0}$ & $21 \mathrm{~V}$ \\
$U_{a 0}$ & $18 \mathrm{~V}$ \\
$R_{a}$ & $0,0035 \Omega$ \\
$K_{3}$ & $0,533 \mathrm{~V} / \mathrm{mm}$ \\
$K_{4}$ & $6,359 \cdot 10^{-4} \mathrm{~V} / \mathrm{Amm}$ \\
$L$ & $100 \mu \mathrm{H}$ \\
\hline
\end{tabular}


$R(t)=-0.001\left[\sin \left(500^{*} p i\right)\right]+0.011$

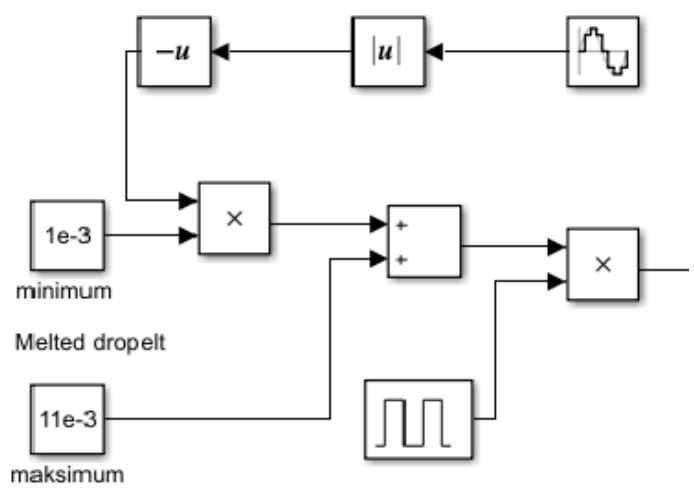

Fig. 6 Simulink model of voltage change of the melted droplet during the short circuit period

Initial parameters are taken from [?]. The process was recorded with a multichannel camera and registered via computerised equipment sensors. The model is adjusted in fixed steps. During the arc period, length has a linear character. That change is related to welding current, rate of reaching the wire, and rate of wire melting. Arc length is set as a linear decreasing function with an initial value that is 1,2 times greater than the wire diameter, and it is modelled as a decreasing line during the arc period.

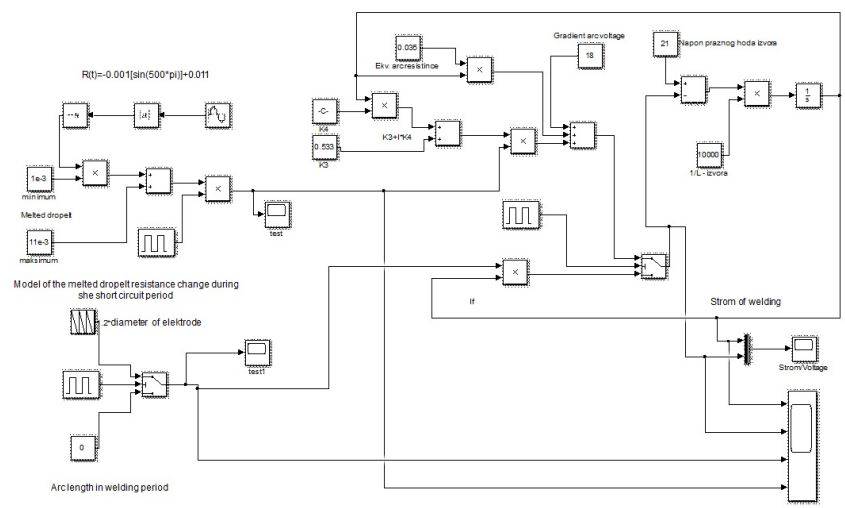

Fig. 7 Simulink model of metal transmission via a short circuit duting the MIG welding process

Effects of initial droplet bridge diameter and short circuit strength have an impact on short circuit duration that reduces as welding current intensity rises and droplet bridge diameter drops. Initial droplet bridge diameter has a greater impact on the short circuit period than the welding current, Figure 9.

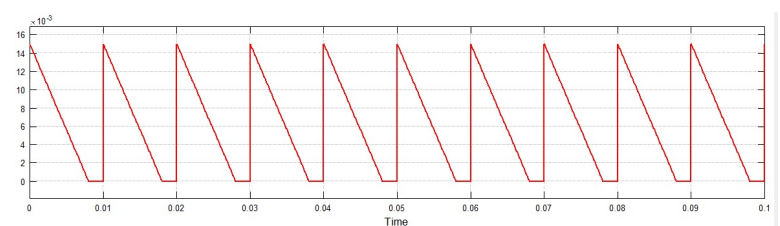

Fig. 8 Model of arc length change during the arc period

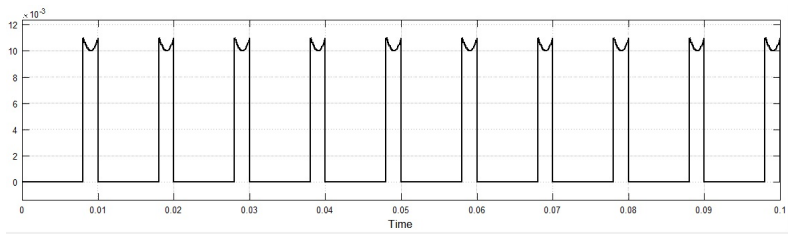

Fig. 9 Model of the melted dropelt resistance change during she short circuit period

In practice, the connection between droplet bridge, welding current and short circuit period is such that greater droplet bridge volume means longer short circuit period, and it requires greater welding current which affects the droplet bridge and accelerates breaking of the bridge.

Effects of protecting gas on periods of short circuit

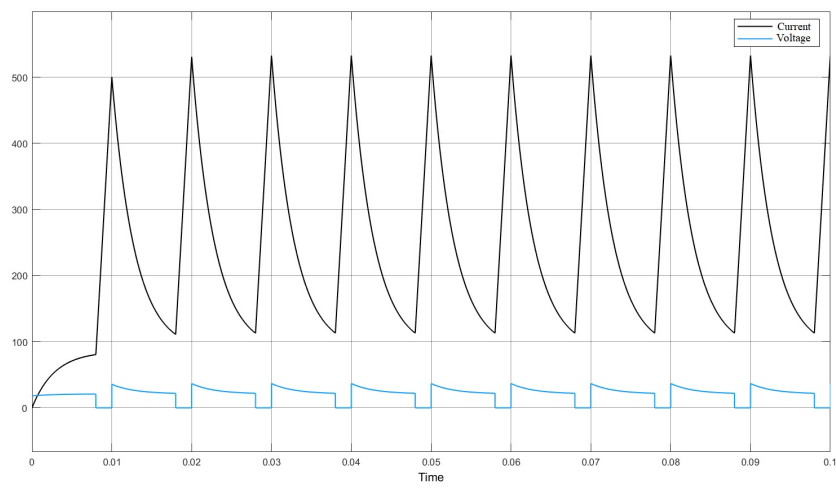

Fig. 10 Voltage waveforms and welding current intensity

and an open arc mostly have an impact on variations that occur due to surface tension of the droplets and arc pressure that affect the said droplets. If we were to use pure Argon, there would not be enough active particles in the arc, and so the droplet would grow slowly due to its surface tension. Rise in peak value of the welding current whilst welding with an inert protective Argon will reduce duration of the arc period and increase the duration of the short circuit period. Voltage waveforms and welding current intensity (Figure 10) approximately correspond to real forms that can be obtained by practical measuring of the process with an oscilloscope. 
Figure 11 shows voltage waveforms and welding current in the simulation where changes in waveforms during arc and short circuit periods can be clearly followed.

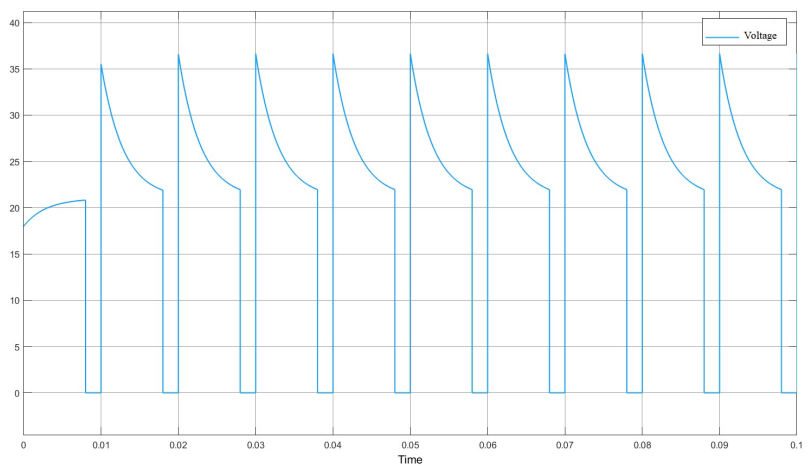

Fig. 11 Voltage waveforms in the simulation

\section{Conclusion}

This paper describes the electric arc in the process of electric-arc welding with transmitting metal via a short circuit. Equipment needed for the process of electric-arc welding is described, as well as process parameters and their effect on the electric arc. Occurrences in the electric arc and the effects of a change in parameters on electric arc stability are described. A model simulated metal transmission via a short circuit during the process of electric-arc welding. Taken input parameters of the model were obtained by the means of real sensor observation of the procedure. Modelling of the process is one of the best ways to examine quality improvement of the electric arc in welding.

\section{References}

1. Zuo Shiwei, He Jianping, Wang Fuxin, Xiang Feng (2011) Modeling and simulation of short-circuiting transferring in GMAW, Shanghain University,

2. M. Usiho, W. Mao (2009) Modeling of an arc sensor for DC MIG/MAG welding in open arc mode: Study of improvement of sensitivity and realibility of arc sensors in GMAW welding. Osaka University

3. J.-P. Planckaert, El-H. Djermoune, D. Brie, F. Briand, F. Richard (2009) Model in gof MIG/MAG welding with experimental validation using anactive contour algorithm applied on high speed movies

4. K. Weman (2012) Welding processes handbook, SE

5. P. Jiluan,(2003) Arc welding Control, Cambridge England

6. Yi Huang, (2011) Control Of Metal Transfer At Given Arc Variables, University of Kentucky,

7. E. F. da Silva, J. R. Macedo. Jr, A. Scotti, J. C. de Oliveira (2008) Power quality analysisof Gas Metal Arc Welding process operating under different drop transfer modes
8. S. Kodama, Y. Ikuno, Y. Ichiyama, N. Baba (2007) Process Modeling of Short-Circuiting GMA Welding and Its Application to Arc Sensor Control, NIPPON STEEL technical report No. 95

9. J. Sandberg Thomsen (2005) Advanced Control Methods for Optimization of Arc Welding, Ph.D. Thesis, Department of Control Engineering, Aalborg University

10. H. Choi, J. Y. Lee, C. D. Yoo (2001) Simulation of Dynamic Behaviorin a GMAW System, supplement to the Welding journal

11. M. Ushio, W. Mao (2010) Dynamic characteristics of an arc sensorin GMA welding in droplet transfer mode: Study of improvement of sensitivity and relibility of arc sensors in GMA welding (3rd Report), Osaka University

12. S. Kou (2003) Welding metallurgy, second edition, University of Wisconsin

13. M. Vural (2014) Welding process and thnologies, Instanul Technical Universety

14. Z. Lukačević (1998) Zavarivanje, Sveučilište Josipa Juraja Strossmayera u Osijeku, Strojarski fakultet Slavonski Brod

15. Z. Lukačević, I. Samardžić (1999) Mogućnost praćenja glavnih parametara pri elektrolučnim postupcima zavarivanja, Zavarivanje 42, Hrvatsko društvo za tehniku zavarivanja, Zagreb.

16. M.Gojić (2003) Tehnike spajanja i razdvajanja, Metalurški fakultet Sisak

17. S. Kralj, Š. Andrić (1992) Osnove zavarivačkih i srodnih postupaka, Sveučilište u Zagrebu, fakultet strojarstva i brodogradnje, Zagreb 